Sādhanā Vol. 40, Part 2, April 2015, pp. 487-502. (C) Indian Academy of Sciences

\title{
Numerical simulation of side heating for controlling angular distortion in multipass MMAW butt welded plates
}

\author{
ADINATH V DAMALE ${ }^{1, *}$ and KESHAV N NANDURKAR ${ }^{2}$ \\ ${ }^{1}$ Department of Mechanical Engineering, College of Engineering Kopargoan \\ (Affiliated to University of Pune), Dist. Ahmednagar 423 603, India \\ ${ }^{2}$ K. K. Wagh. Institute of Engineering Education and Research, Nashik (Affiliated to \\ University of Pune), Nashik, 422 003, India \\ e-mail: adi_damale@yahoo.com; keshav_1965@gmail.com
}

MS received 25 December 2013; revised 28 July 2014; accepted 6 November 2014

\begin{abstract}
Distortion is a severe problem in weld products.It depends on various process parameters like plate thickness, current, voltage, type of weld joint and restraints put on. If distortion is not properly dealt during welding then the product may become useless from geometric accuracy point of view. In the present study, a 3-D coupled transient thermal analysis model with auxiliary side heating (parallel heating) is developed to control angular distortion. During analysis, parallel heating flames are placed at several locations from weld line in cross direction. A user defined subroutine is used to apply transient heat source and side heating flames. Element birth and death technique is used to simulate the filler material deposition. One side multipass ' $\mathrm{V}$ ' butt weld configuration is used for this study. A series of observational tests are done with a special experimental fixture using Manual Metal Arc Welding (MMAW) to validate the proposed FEA model. It is found that the angular distortion has decreased from $2 \mathrm{~mm}$ to $0.4 \mathrm{~mm}$ with change in side heating distance from 50 to $90 \mathrm{~mm}$ from the weld line.
\end{abstract}

Keywords. Side heating; finite element analysis; element birth and death method; manual metal arc welding; angular distortions.

\section{Introduction}

Welding is preferred over all mechanical joining processes because it offers advantages such as flexibility in design, cost savings, reduced overall weight and enhanced structural performance. However, it induces various types of distortions like angular, transverse, longitudinal, etc. Distortions induced by welding have been regarded as a critical issue in terms of performance, quality and productivity. Angular distortion is the most pronounced type of distortion which badly affects the quality of weld structures. The fundamental cause of the welding-induced distortion

${ }^{*}$ For correspondence 
is the non-uniform heating of material during the welding process, which in turn produces plastic strains and residual stress owing to the mismatch of thermal expansions in the weld and surrounding material. The residual stress and plastic strain are inherent in the welding process: they interact to produce distortion in welded structures. Mandal (2004) claims that, in certain applications, this distortion may result in the structure being useless. High costs through post weld heat treatments and other rectification methods are required to rectify these welding distortions (Jung \& Tsai 2004).

During the past few decades, many methods have been proposed to minimize the weldinginduced distortion in large structures (Camilleri et al 2005). These methods can be classified into design-based and manufacturing-based. Design-based approaches attempt to balance the residual stress by optimizing the structural design, fixturing design, and welding sequence (Dean \& Murukawa 2008a, b). These approaches can only reduce the welding-induced distortion to a certain extent, limited by the original structural and welding process design. Process-based approaches, on the other hand, aim to minimize the residual stress during the welding process for given structures and welding sequences. Most of these methods provide pretensions through mechanical or thermal means to compensate for the welding-induced mismatch of the thermal expansion. Damale \& Nandurkar (2012) used the applied restraint method for reducing the MMAW developed angular distortion. Chakravarti et al (1990) attempted effectiveness of certain procedures, which involve stretching loads, preheat, different heat inputs and restraints, in reducing angular distortion of bead on panel welds. Camilleri et al (2005) used thermal contraction strain' (TCS) and 'mismatched thermal strain' (MTS) to control distortions. FE model was used to predict the distortion of the curved structure by Dean \& Murukawa (2008a, b). Zhang et al (2007) used external restraints and heat sinking for reducing GTAW produced distortions. Moraitis \& Labeas (2009) had used the Laser beam welded specimens to predict the residual stresses and distortions. Long et al (2009) predicted the distortion in MIG welded butt welds through EF technique. Nishikawa et al (2007) developed an Interactive Substructure Method (ISM) as an approach to reduce the computational time in three-dimensional FE analyses of welding. Costa et al (2010), numerically modelled the residual stresses in ND-YAG LASER welding. Zhang et al (2007) predicted the welding distortion using the applied plastic strain method. Adak \& Mandal $(2009,2010)$ used the concept of Pseudolinear to model the welding phenomenon and predict the welding distortion. Also they studied the effect of heat sinking on angular distortion of SAW. Kim et al (2009) had mentioned the importance of estimation of weld distortions and residuals stresses for designing and fabricating stable welded structures. Effect of SMAW process parameters on temperature distributions and weldment zones in butt and one sided fillet welds have been studied by Mahapatra et al (2006).

According to Tsai et al (1999), FEM techniques has been used in the prediction of welding residual stress and distortion for more than two decades. Additional complexities are involved in the FEA of welding compared with other thermo-mechanical processes. Because factors such as temperature dependent material properties, high gradients of temperature, stress and strain fields with respect to both time and spatial coordinates, large deformations in thin structures, phase transformation and creep phenomena (Radaj 1992) make it difficult for FE analysis of arc welding. Earlier studies of welding accounted for the non-linearities caused by temperature dependent material properties and plastic deformations. The conventional Manual Metal Arc Welding process is often troubled with large welding-induced distortion owing to production variations such as the dimensional imperfection of the plates and uneven heat inputs.

A predictive analysis technique can determine the susceptibility of a particular design to angular distortion. Furthermore, a predictive analysis tool can assist in the selection of geometry and 
welding conditions which will minimize angular distortion. Flame straightening is one of the available methods used to correct buckling distortion resulting from welding processes but it is a labour intensive and costly process. Moreover, it is a corrective action after the damage is done rather than a preventive measure (Radaj 1992), which is generally undesirable in engineering processes.

The objective of the present study is to develop a transient thermal side heating strategy for welding distortion control of one-sided multipass butt welds which are commonly used in the heavy equipment industries. It proposes the use of auxiliary side heating to in-process control an angular distortion of butt welded plates. The distance of auxiliary side heating flame nozzles from the weld line governs the nature and magnitude of angular distortion and residual stresses. However, effects of side heating on residual stresses are beyond the scope of this paper. The analysis is carried out using Finite Element Method (FEM) followed by experimental verification to validate the developed FE model.

\section{Finite element modelling}

\subsection{Principle of distortion control}

Distortion in a weld results from the expansion and contraction of the weld metal and adjacent base metal during the heating and cooling cycle of the welding process. The weld zone material gets rapidly cooled and it shrinks faster than the adjacent base metal of work piece. The reduced temperature gradient between weld zone and adjacent metal due to side heating will heat the workpiece more uniformly than conventional MMAW welding. This uniform heating will also result in more uniform cooling resulting in less shrinkage i.e. reduced distortion in workpiece. So, in this paper an in-process method for controlling angular distortion in one sided butt weld is developed, in light of the above-described background.

\subsection{Thermal model}

The FEM procedure used for simulation of MMAW is shown in figure 1. In the finite element simulation, the temperature history of welding is first calculated in a thermal analysis procedure. The temperature field output is then loaded into a structural analysis to calculate the weldinginduced distortion.

The governing equation of the welding process is the standard transient heat conduction equation,

$$
\rho c \frac{\partial T}{\partial t}=\mathrm{q}+\frac{\partial}{\partial x}\left[K_{x} \frac{\partial T}{\partial x}\right]+\frac{\partial}{\partial y}\left[K_{y} \frac{\partial T}{\partial y}\right]+\frac{\partial}{\partial z}\left[K_{z} \frac{\partial T}{\partial z}\right],
$$

where $\rho$ is the density, $\mathrm{c}$ is the specific heat of the steel, $\mathrm{q}$ is the heat generation rate per unit volume, $\mathrm{T}$ is the instantaneous temperature at any point in the domain, $\mathrm{T}=\mathrm{T}(\mathrm{x}, \mathrm{y}, \mathrm{z}, \mathrm{t})$, and $\mathrm{k}_{\mathrm{x}}, \mathrm{k}_{\mathrm{y}}$, and $\mathrm{k}_{\mathrm{z}}$ are the thermal conductivity of the material on $\mathrm{x}, \mathrm{y}$ and $\mathrm{z}$ directions, respectively. Since the steel plate is homogeneous, isotropic material properties are used. Thus, $\mathrm{k}_{\mathrm{x}}=\mathrm{k}_{\mathrm{y}}=\mathrm{k}_{\mathrm{z}}$ in the model. Usually the heat generation term $\mathrm{q}$ in the equation can be used as the heat input from the Gaussian distribution heat source. In this model, the heat input is applied as temperature loads directly on the nodes that are associated with welding (figure 1). Therefore, $q$ is set to zero in the model. The initial temperature loads are applied uniformly to the welding areas. Before the welding process starts, the initial temperature on the structure is set to the room temperature. 


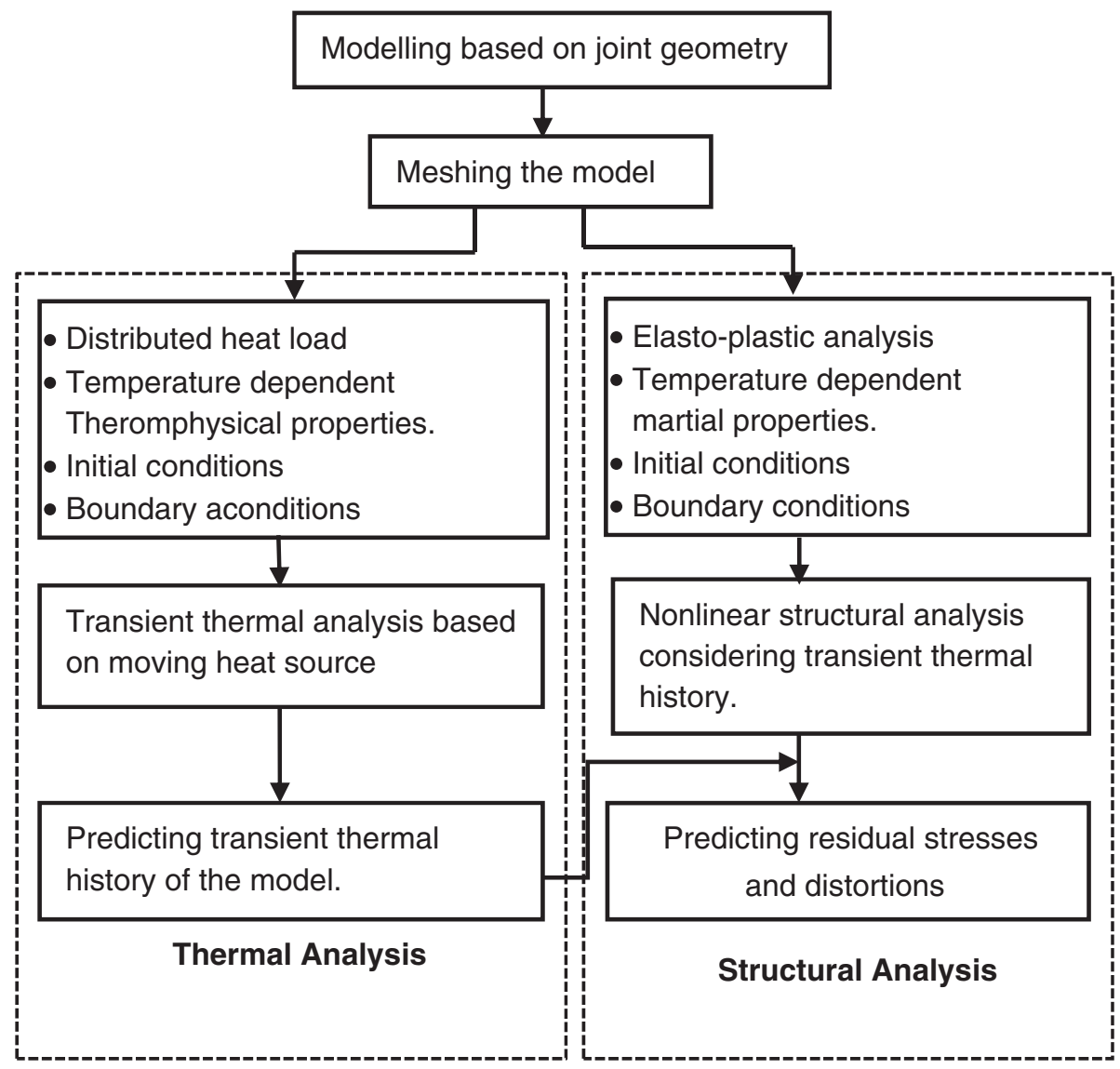

Figure 1. 3D-Coupled thermo mechanical analysis of MMA welding.

During welding and cooling, convection boundary condition is applied to all the free surfaces of the plate. The heat loss flux is evaluated as

$$
\mathrm{q}_{\mathrm{s}}=-\mathrm{h}_{\mathrm{f}}\left(\mathrm{T}_{\mathrm{s}}-\mathrm{T}_{0}\right),
$$

where $\mathrm{h}_{\mathrm{f}}$ is the convective heat transfer coefficient or the film coefficient, $\mathrm{T}_{\mathrm{s}}$ is the surface temperature, and $\mathrm{T}_{\mathrm{O}}$ is the room temperature. Radiation heat loss is ignored in the model (Mahapatra et al 2006). The film coefficient is assumed to location dependent, however it changes with temperature.

2.2a Addition of filler material: In FEA of welding, addition of filler material is important because the nature of process is transient. The added heat flux and mass change continuously with respect to time. To achieve this, a special tool known as 'element birth and death' is used. The element birth and death procedure is generally used to analyse excavation, staged construction, sequential assembly, and many other applications in which the elements can be easily identified, activated, or deactivated by their known locations. To achieve the 'element death' effect, the finite element analysis (FEA) program does not actually remove the elements. Instead, 
it deactivates them by multiplying their stiffness (or conductivity, or other analogous quantity) by a severe reduction factor. Similarly, when elements are 'born', they are not actually added to the model, but are simply reactivated. When an element is reactivated, its stiffness, mass, element loads, etc. return to their full original values. The elements are reactivated with no record of strain history or heat storage. In this model, separate elements are used to represent the three weld pass. Weld bead elements are modelled before the analysis and elements of respective weld pass are considered for different weld passes. These elements are deactivated initially before welding. With the movement of the welding torch, all the deactivated elements are reactivated when the welding torches pass their locations. Thus elements are made inactive and active as the weld heat source moves with respect to time.

\subsection{Assumption}

As far as possible the actual welding conditions were considered in the thermal model. However, the following assumptions are still required.

(i) All the thermal properties are considered to be a function of the temperature.

(ii) Linear Newtonian convection cooling is considered on all the surfaces.

(iii) The heat loss due to radiation, conduction through the electrode, and heat consumed by burning of the flux and melting of the electrode were accounted for by the arc energy transfer efficiency parameter $\eta$. In the present study, a value of 0.75 is taken for $\eta$ for the SMAW process (AWS Weld Handbook 2004).

(iv) A constant convection coefficient of $15 \mathrm{~W} / \mathrm{m}^{2} \mathrm{~K}$ is considered.

(v) Heat flux is considered as a load.

(vi) A birth-and-death technique is used in this model to simulate the formation of a weld bead through metal deposition. Thermal profiles are obtained by applying layer-wise heat flux for each pass of welding and considering filler material deposition (figure 2).

The thermomechanical properties of mild steel used for modelling temperature distributions and distortions are shown in table 1 . Solidus $\left(\mathrm{T}_{\text {solidus }}\right)$ and liquidus $\left(\mathrm{T}_{\text {liquidus }}\right)$ temperatures of the mild steel used in the analysis are considered to be 1435 and $1500^{\circ} \mathrm{C}$, respectively. The density of the mild steel used in the analysis is taken as $7850 \mathrm{~kg} / \mathrm{m}^{3}$ (ASM Handbook Vol-II 2005). A schematic diagram of a one-sided but joint with uniformly meshing is shown in figure 3. The element type in thermal analysis is SOLID70 (linear 8-node brick element with one degree of freedom, i.e., temperature at each node) and in structural analysis is SOLID45 (linear 8-node brick element with three degrees of freedom at each node: translations in the nodal $\mathrm{x}, \mathrm{y}$, and $\mathrm{z}$ directions). The geometric parameters for each of the three weld passes (figure 2) is obtained through macrographs of test pieces welded by conventional MMAW process. In arc welding, the moving heat source/heat flux may be modelled as a surface heat source which is a heat generated over a certain area $\left(\mathrm{J} / \mathrm{m}^{2} \mathrm{~s}\right)$. The heat flux be uniformly distributed or distributed according to a Gaussian distribution. Various heat source models are proposed in the literature. According to Goldak et al (1984), the heat source can also be represented as a volumetric heat source $\left(\mathrm{J} / \mathrm{m}^{3} \mathrm{~s}\right)$. The Volumetric heat source is a body heat load applied to a certain volume. This paper uses the moving surface heat load with Gaussian distribution. The heat flux in FEA is applied by Eq. 3. The similar heat source model is used by Adak \& Mandal $(2009,2010)$. The moving heat load is applied on the area bounded by the weld lines as shown in figure 3. Except this area, other areas of the plate are subjected to heat loss due to convection. 


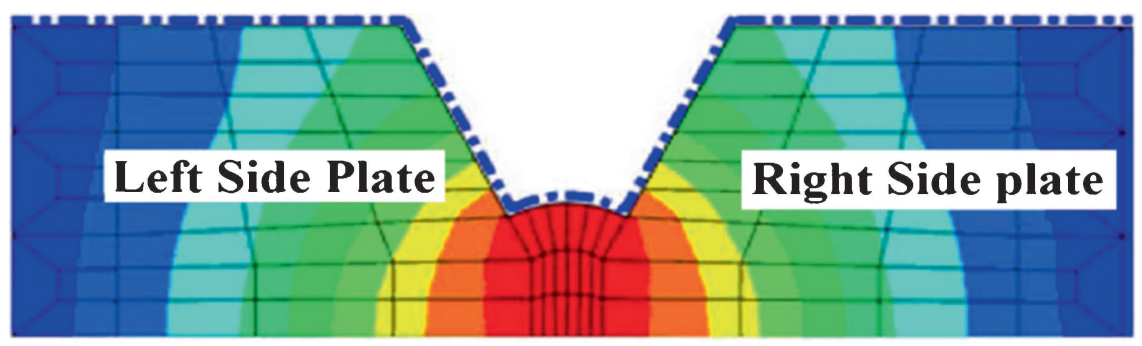

(a) First pass

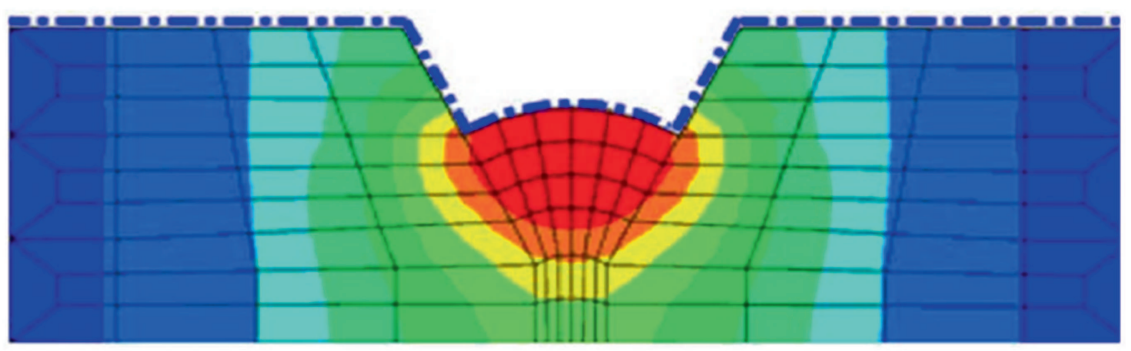

(b) Second Pass

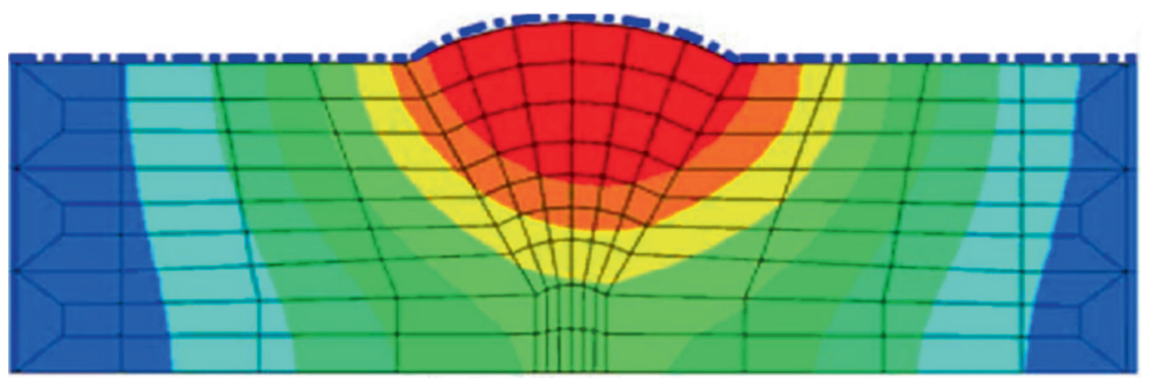

(c) Third pass

Figure 2. Application of moving heat for each passes in FE Model.

The author defined virtual moving heat source along with side heating nozzles is shown in figure 4 . In this analysis, the convection loss is taken as $15 \mathrm{~W} / \mathrm{mK}$ (ASM Handbook 2005), and the supplied heat flux is applied using Eq. (3).

$$
Q_{\sup (r)=\frac{3 Q e}{\pi \bar{r}^{2}} \exp \left[-3\left[\frac{r}{\bar{r}}\right]^{2}\right]},
$$

where, $r^{2}$ is the effective area over which the heat flux is applied, and is given by $r^{2}=x^{2}+y^{2}$ where $\mathrm{x}, \mathrm{y}$ are the Cartesian coordinates in the weld zone whereas $\bar{r}$ is the region in which $95 \%$ of heat flux is concentrated (Adak \& Mandal 2009, 2010) and $\mathrm{Q}_{\mathrm{e}}=\eta \mathrm{VI}$. Where $\eta$ is the arc efficiency, $\mathrm{V}$ is the voltage and $\mathrm{I}$ is the current. The values of $\mathrm{x}$ and $\mathrm{y}$ in Eq. (3) are changing continuously with time making it an incremental in nature for calculating surface heat flux. Heat flux is calculated for different values of $\mathrm{X}$ and $\mathrm{Y}$ positions of arc weld with time and then are put in the tabular form. These tabular values are applied as heat flux in FEA model. 


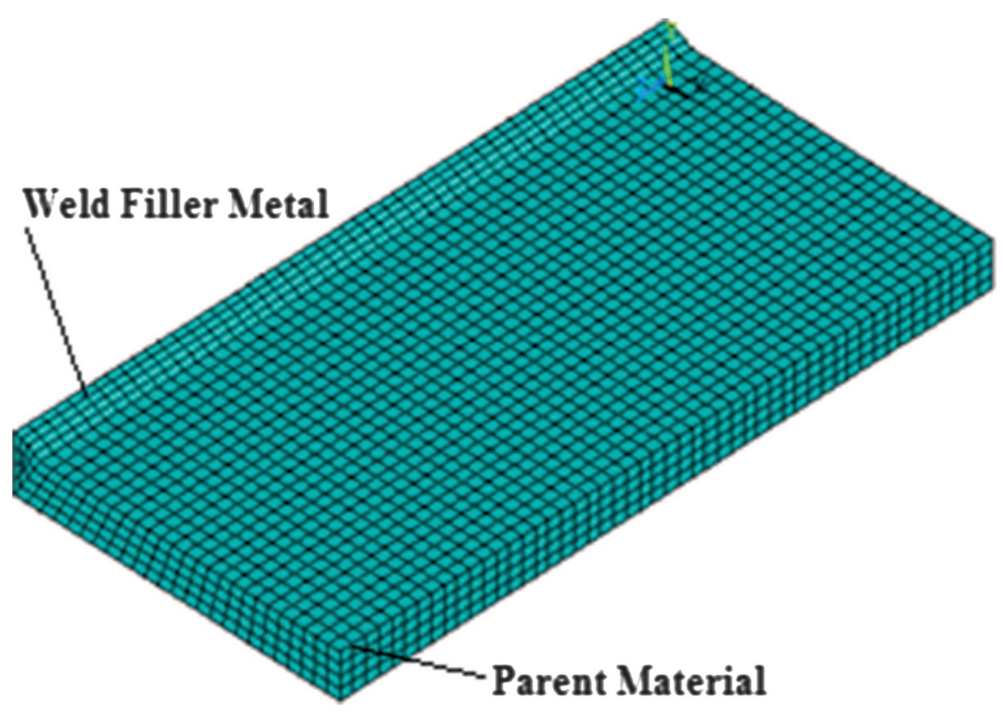

Figure 3. Half meshed plate.

To minimize the requirement of memory and analysis time, half of the plate (figure 3 ) is modelled due to the axisymmetric conditions. Welding was performed in the direction of $\mathrm{P}$ to $\mathrm{R}$ (figure 5). Side heating flames were placed along the paths AA', BB', CC', DD' and EE' at a distance of 50,60,70,80 and $90 \mathrm{~mm}$, respectively from weld line. Angular distortions with respect to the reference points (points a, b, c, d, and e on edge along length in figure 5) are measured before and after welding. As the arc welding is transient and quasi-static phenomenon (Radaj 1992), therefore transient thermal and nonlinear structural analysis is carried out for predicting angular distortion.

During analysis (both thermal and structural), a 'Full Newton-Raphson' iterative solution technique with a direct sparse matrix solver is used for obtaining the solution. During the thermal cycle, temperature, and consequently temperature-dependent material properties, change very rapidly; thus, a Full Newton-Raphson scheme, which uses a modified material properties table and reformulated stiffness matrix after equilibrium iterations, is believed to give more accurate results than other options such as Modified or Initial Newton-Raphson schemes. Line search option of the FE code ANSYS is set to ON to improve convergence. A total of 100 load steps are used during analysis. The use of a single point reduced integration scheme is implemented with hourglass control to facilitate convergence and to avoid excessive locking during structural analysis.

Five test cases are prepared for the present analysis. The FE model is further verified by comparing predicted and experimentally obtained angular distortions. The composition of mild steel plates used in the experiments is shown in table 2 .

\subsection{Structural model}

The structural analysis involves large displacements (strain) and a rate-independent thermoelasto-plastic material model with temperature-dependent material properties incorporated into the modelling. The plastic deformation of the material is assumed to obey Von Mises yield 


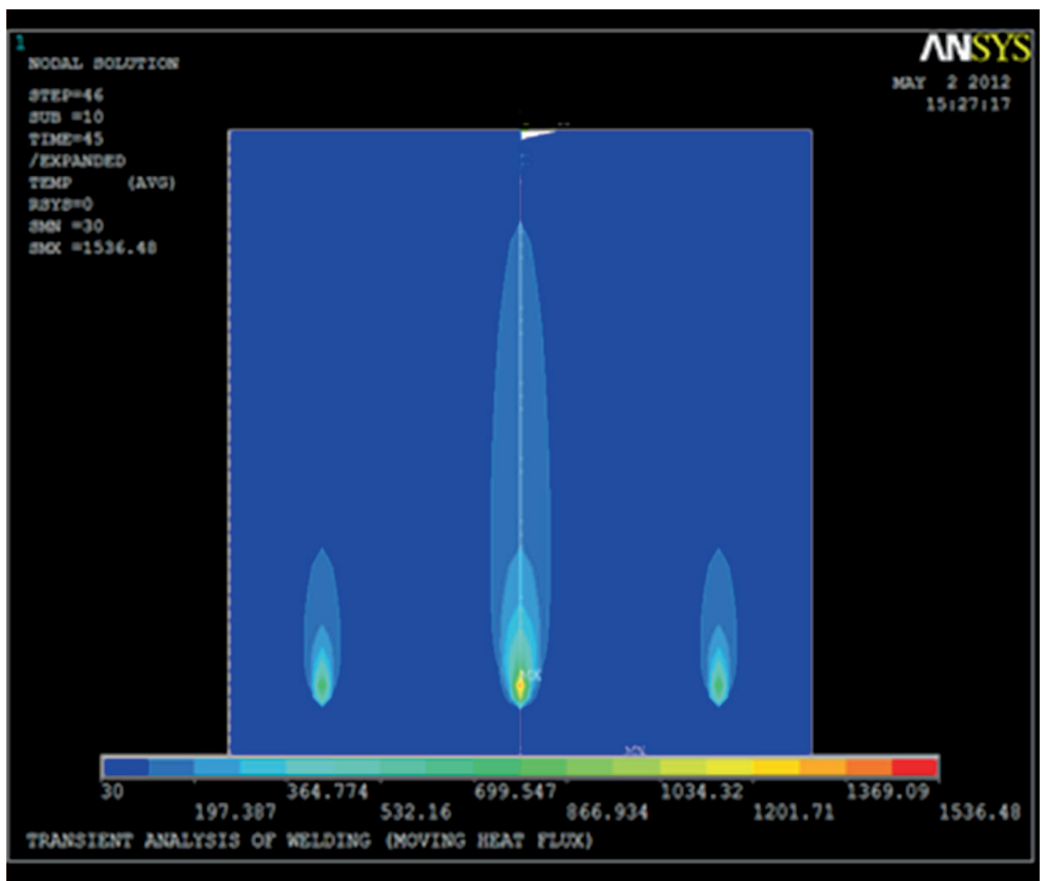

Figure 4. FE side heating transient heat model.

criterion. The following thermal elastic-plastic constitutive equations are used in the mechanical (stress) simulation (ANSYS Inc 2013):

$$
[d \sigma]=\left[D^{e p}\right][d \varepsilon]-\left[D^{t h}\right] d T
$$

and

$$
\left[D^{e p}\right]=\left[D^{e}\right]+\left[D^{p}\right]
$$

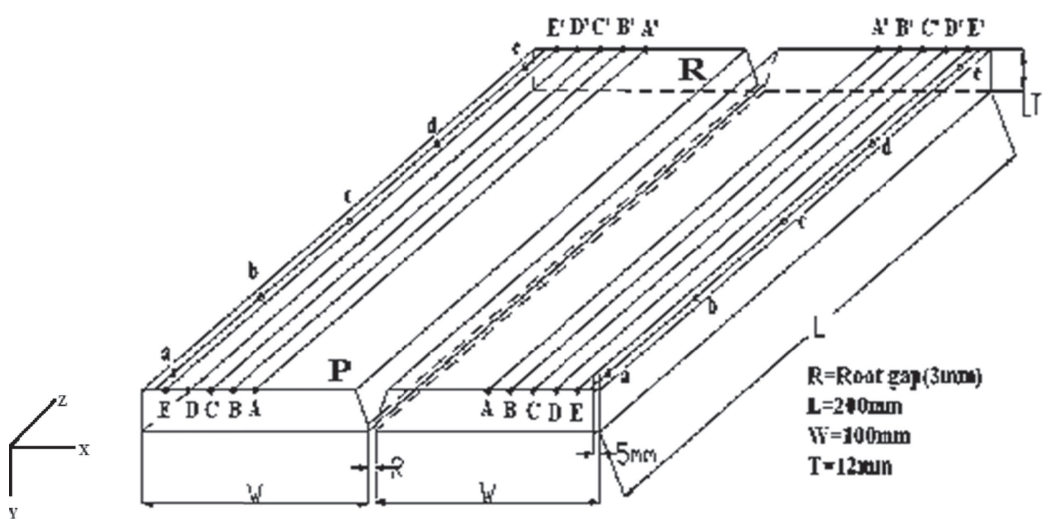

Figure 5. Welding specimen with side heating paths and grid points for measuring distortion. 
Table 1. Thermal and mechanical properties of mild steel (ASM Handbook Vol-II 2005).

\begin{tabular}{llllllll}
\hline $\begin{array}{l}\text { Temperature } \\
\left({ }^{\circ} \mathrm{C}\right)\end{array}$ & $\begin{array}{c}\text { Thermal } \\
\text { conductivity } \\
(\mathrm{W} / \mathrm{mK})\end{array}$ & $\begin{array}{c}\text { Specific } \\
\text { heat } \\
(\mathrm{J} / \mathrm{kgK})\end{array}$ & $\begin{array}{c}\text { Enthalpy } \\
\left(\mathrm{J} / \mathrm{m}^{3}\right)\end{array}$ & $\begin{array}{c}\text { Poison's } \\
\text { ratio }\end{array}$ & $\begin{array}{c}\text { Yield } \\
\text { Stress } \\
(\mathrm{MPa})\end{array}$ & $\begin{array}{c}\text { Young's } \\
\text { modulus } \\
(\mathrm{GPa})\end{array}$ & $\begin{array}{c}\text { Coefficient of } \\
\text { thermal } \\
\text { expansion } \\
\left(10^{-6} /{ }^{\circ} \mathrm{C}\right)\end{array}$ \\
\hline 0 & 51.9 & 450 & $1 \times 10^{9}$ & 0.2786 & 290 & 200 & 10 \\
100 & 51.1 & 499.2 & $2 \times 10^{9}$ & 0.3095 & 260 & 200 & 11 \\
300 & 46.1 & 565.5 & $2.65 \times 10^{9}$ & 0.331 & 200 & 200 & 12 \\
450 & 41.05 & 630.5 & $3.8 \times 10^{9}$ & 0.338 & 150 & 150 & 13 \\
550 & 37.5 & 705.5 & $4.1 \times 10^{9}$ & 0.3575 & 120 & 110 & 14 \\
600 & 35.6 & 773.3 & $4.55 \times 10^{9}$ & 0.3738 & 110 & 88 & 14 \\
720 & 30.64 & 1080.4 & $5 \times 10^{9}$ & 0.3738 & 9.8 & 20 & 14 \\
800 & 26 & 931 & $5.23 \times 10^{9}$ & 0.4238 & 9.80 & 20 & 15 \\
1450 & 29.45 & 437.93 & $9 \times 109$ & 0.4738 & 7.30 & 2 & 15 \\
1510 & 29.7 & 400 & $1.1 \times 10^{10}$ & 0.499 & 1.36 & 0.2 & 15.3 \\
1580 & 29.7 & 735.25 & $1.1 \times 10^{10}$ & 0.499 & 0.0098 & 0.00002 & 15.4 \\
5000 & 42.2 & 400 & $1.25 \times 10^{10}$ & 0.499 & 0.0098 & 0.00002 & 15.5 \\
\hline
\end{tabular}

where $d \sigma$ denotes the stress increment, $d \varepsilon$ denotes the strain increment, $d T$ denotes the temperature increment, $\left[D^{e}\right]$ denotes the elastic stiffness matrix, $\left[D^{p}\right]$ denotes the plastic stiffness matrix, and $\left[D^{t h}\right]$ denotes the thermal stiffness matrix. Plastic strains resulting from transformation plasticity and rate-dependent plastic flow are not considered in the model. The thermo-elastic-plastic material behaviour is assumed to follow an isotropic bilinear kinematic hardening model. For each pass of welding, temperature history from thermal analysis in every load step was used as the thermal loading in the structural analysis. Boundary conditions that prevented rigid body motions were imposed into the modelling. The solution is obtained using the ANSYS ${ }^{\circledR}$ package. A user defined subroutine was developed in APDL (ANSYS Parametric Design Language) for performing analysis. Figure 6 shows distorted weld specimen after FEA.

\section{Experimental details}

Validation of the developed FEA model is done using Manual metal arc welding (MMAW). Test samples are carried out with various combinations of welding speeds and current. As MMAW can be performed in AC and DC mode, in the present analysis, DC mode with electrode connected to the positive terminal and workpiece to the negative terminal i.e. DCEP is used.

Mechanized speed controlling unit (small trolley) is used to keep the constant speed during the welding. The operator's hand holding welding torch is placed on this mechanized unit during welding and the weld speed is controlled by keeping the constant speed of the unit. A special fixture as shown in figure 7 is developed to apply side heating flame nozzles at varied distance on either side of the weld line.

Table 2. Composition of the steel used in the experiments (ASM Handbook Vol-II 2005).

\begin{tabular}{lccccccc}
\hline $\mathrm{C}(\%)$ & $\mathrm{Si}(\%)$ & $\mathrm{Mn}(\%)$ & $\mathrm{P}(\%)$ & $\mathrm{S}(\%)$ & $\mathrm{Ni}(\%)$ & $\mathrm{Cr}(\%)$ & $\mathrm{Fe}(\%)$ \\
\hline 0.15584 & 0.17774 & 0.45330 & 0.17975 & 0.06918 & 0.1324 & 0.01567 & 98.8413 \\
\hline
\end{tabular}




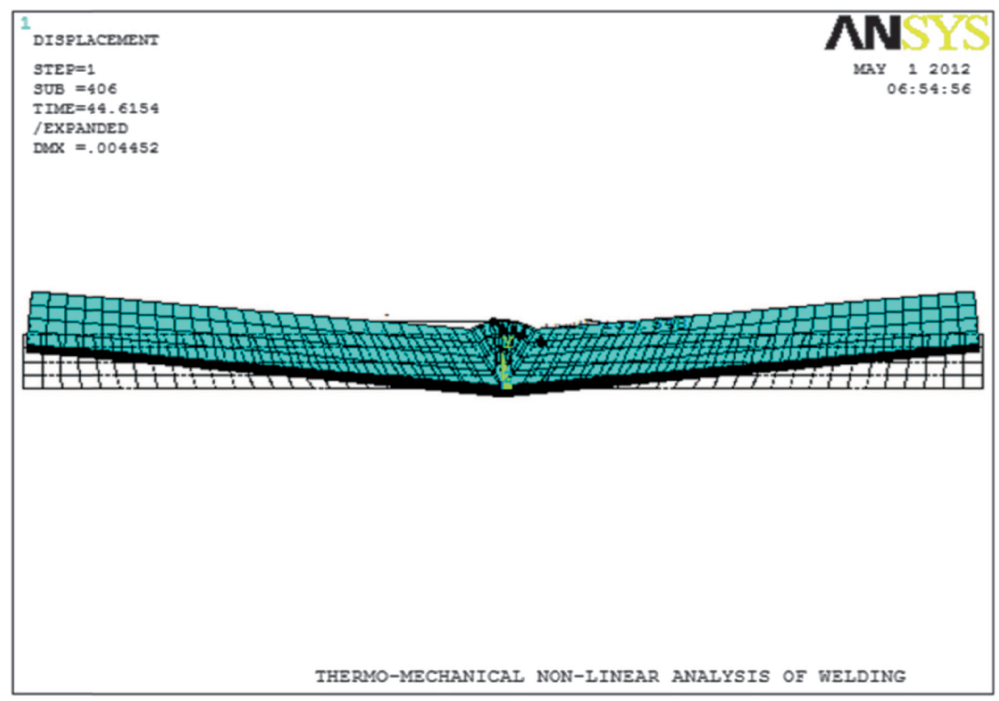

Figure 6. Distorted butt welded specimen after virtual welding.

The length and width of the plates are considered appropriate for finite element modelling purposes, taking into account the moving distributed heat source. Before starting the welding; the plates are tack welded at $10 \mathrm{~mm}$ from both the ends to avoid the in-plane rotation of the plates. A skilled welder is used to perform the welding operation. The filler rods used are of type IS: 814-91: ER $4212 \mathrm{X}$ with $450 \mathrm{~mm}$ length, 2.15 and $4 \mathrm{~mm}$ diameters. First weld pass is performed using $2.15 \mathrm{~mm}$ weld rod and others with $4 \mathrm{~mm}$. The passes were started at point $\mathrm{P}$ and finished at point R (figure 5). A time gap of $1.5 \mathrm{~min}$ is given between the successive passes. This duration is utilized to remove the slag formed during the each pass. Voltage and current during welding are measured with digital meters mounted on the welding machine. The duration of welding is noted down for each weld pass. Knowing the weld length, the speed is calculated.

The welding process parameters of the five test pieces are shown in table 3 . Two different sets of welded specimens were prepared. Five test cases were welded in each set of welding. In

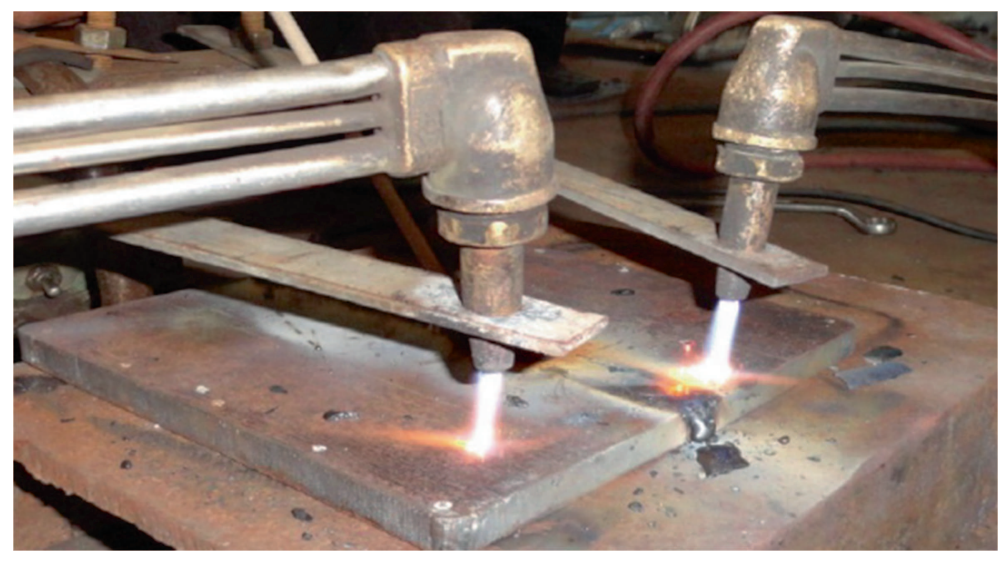

Figure 7. Special fixture for side heating during welding. 
Table 3. Welding process parameters of study.

\begin{tabular}{lcccc}
\hline $\begin{array}{l}\text { Job. } \\
\text { No. }\end{array}$ & $\begin{array}{c}\text { Current } \\
(\text { Amp })\end{array}$ & $\begin{array}{c}\text { Voltage } \\
\text { (Volt) }\end{array}$ & $\begin{array}{c}\text { Welding speed } \\
(\mathrm{mm} / \mathrm{s})\end{array}$ & $\begin{array}{c}\text { Side heating torch distance } \\
\text { from weld arc }(\mathrm{mm})\end{array}$ \\
\hline 1 & 150 & 75 & 3.12 & 50 \\
2 & 160 & 75 & 3.68 & 60 \\
3 & 170 & 75 & 3.95 & 70 \\
4 & 180 & 75 & 4.10 & 80 \\
5 & 185 & 75 & 4.23 & 90 \\
\hline
\end{tabular}

first five test cases, plain welding (i.e., Conventional MMA welding without side heating) was carried out and angular distortions were noted. Subsequently, another set of five test specimens were welded using the side heaters on either side of the weld arc. The side heating nozzles were placed at different positions as shown in table 3. Figure 5 shows the side heating positions marked with letters A-A', B-B', C-C', D-D' and E-E' which were placed at a distance of 50, 60, 70,80 and $90 \mathrm{~mm}$, respectively from weld arc during welding. To measure the angular distortion, the grid points were marked on the workpieces (figure 1). Mechanical dial gauge mounted on the magnetic stand is used to measure the vertical displacement of the plates. Displacements of welded specimens in vertical direction are measured before and after the welding.

\section{FE Model validation approach}

To validate the developed FE model, two approaches namely thermal model validation and structural model validation are used (Damale \& Nandurkar 2013). In thermal model validation approach, welding temperature is measured at some specified points and similar points in FEA model are used to predict the temperature profile which then plotted for comparison. Whereas, post weld distortions are measured at some specified points on test specimens and are compared with similar values predicted by FEA model. In this study, for thermal model validation, transient temperatures of the welding process are measured and then are compared with FE temperatures. Four $\mathrm{K}$ type thermocouples $\left(\mathrm{T}_{1}, \mathrm{~T}_{2}, \mathrm{~T}_{3}\right.$ and $\left.\mathrm{T}_{4}\right)$ are used to measure the welding temperatures. Figure 8 shows the locations of thermocouples placed on the surface of the test specimen. In this figure, $\mathrm{X}_{1}, \mathrm{X}_{2}, \mathrm{X}_{3}, \mathrm{X}_{4}$ and $\mathrm{Z}_{1}, \mathrm{Z}_{2}, \mathrm{Z}_{3}, \mathrm{Z}_{4}$ are the distances of thermocouples $\mathrm{T}_{1}, \mathrm{~T}_{2}, \mathrm{~T}_{3}$ and $\mathrm{T}_{4}$ in transverse and longitudinal direction, respectively. The temperatures are noted for conventional MMAW process because measurement of temperature due to sideheaters is difficult on the test piece surface. The welding process temperatures are recorded at every 2 seconds. Predicted and measured transient temperatures are shown in figure 9. Also, predicted and measured angular displacements are compared to validate the structural model.

\section{Results and discussion}

The accuracy of the developed heat source model depends on its ability to correctly add the heat in the workpieces. Figure 9 shows the predicted and observed transient temperatures of the workpieces. This figure shows close matching between the predicted and measured temperatures which boost the ability of developed numerical model for future use. Also the nature of curves in figure 9 confirms the quasi-static and transient nature of welding process. The predicted and 


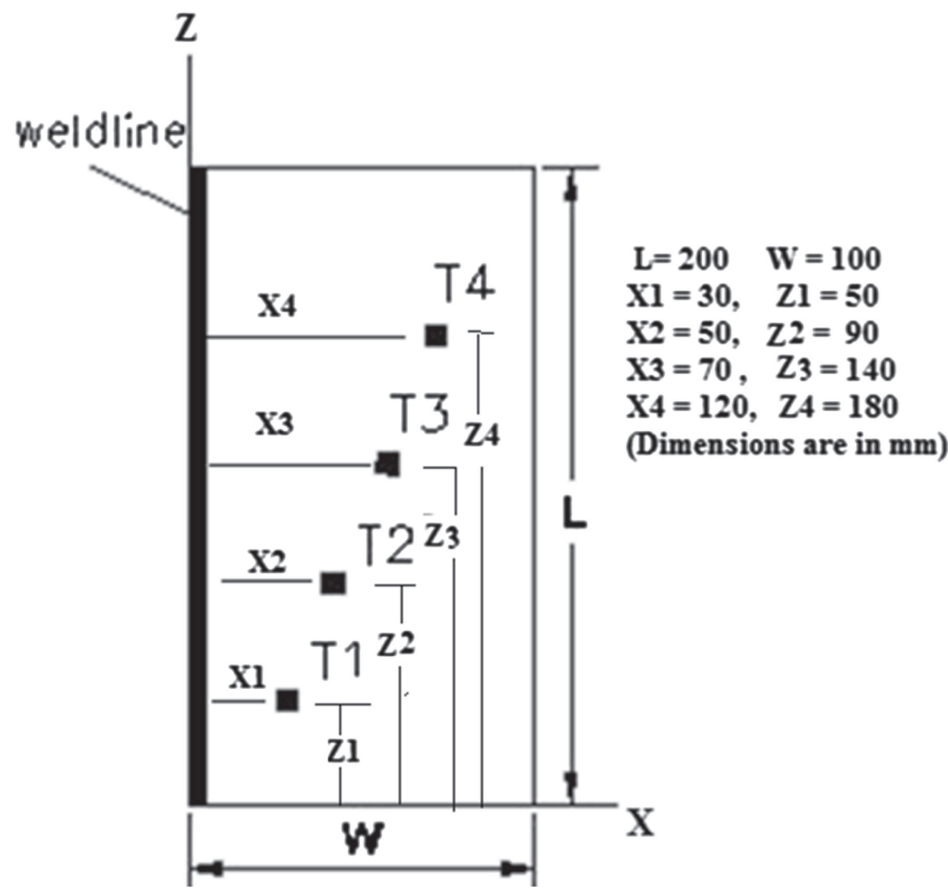

Figure 8. Locations of thermocouples.

measured values of angular distortion at grid points on the specimens are shown in figures 10a-e. The results of the conventional MMAW welding are shown as 'plain welding' whereas side heating/parallel heating results are mentioned as 'side heating'.

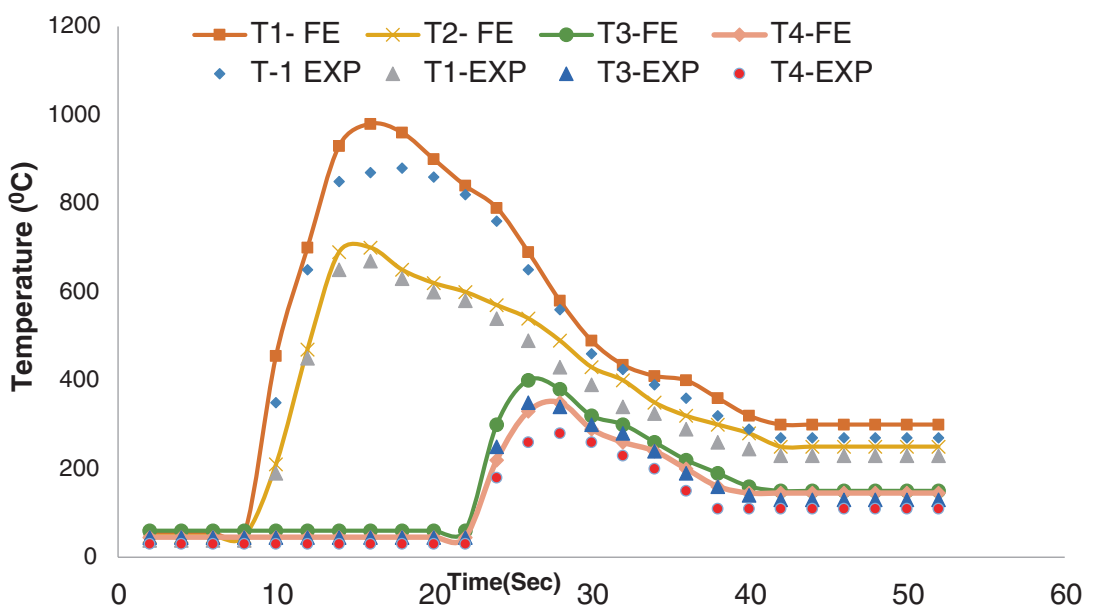

Figure 9. Measured and predicted temperature profile of process. 


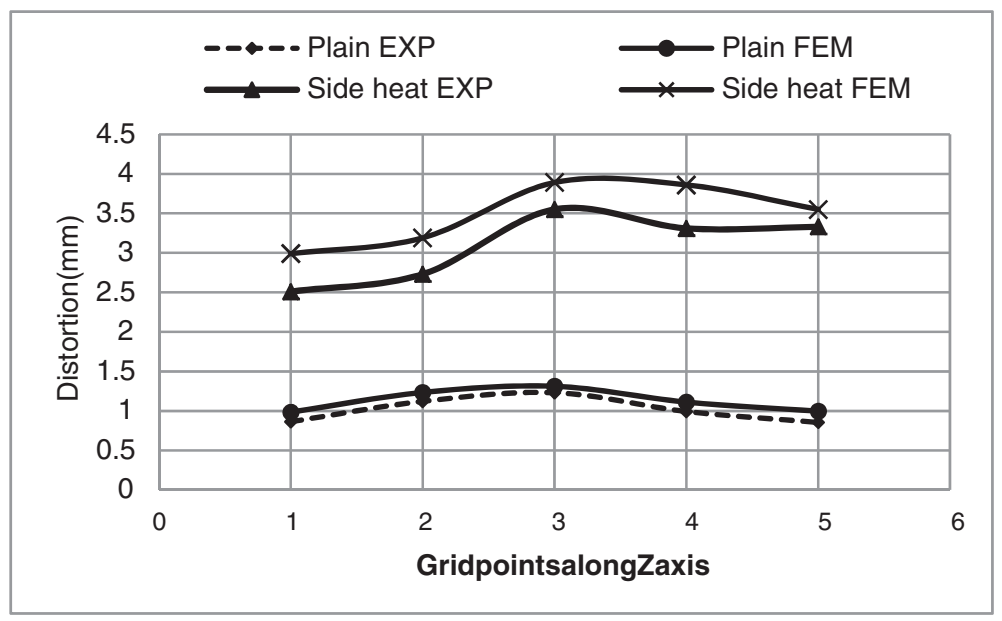

(a) Test Case1 (Side heating at $50 \mathrm{~mm}$ )

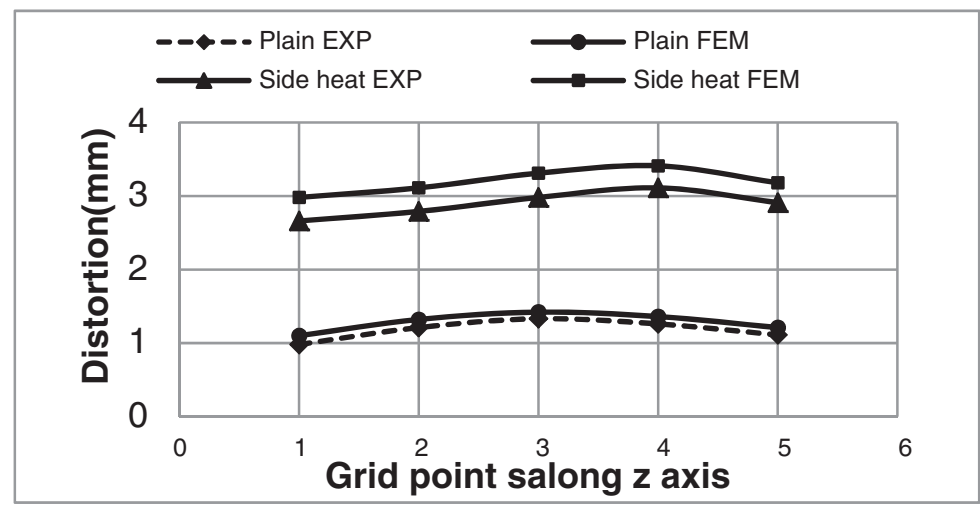

(b) Test Case 2 (Side heating at $60 \mathrm{~mm}$ )

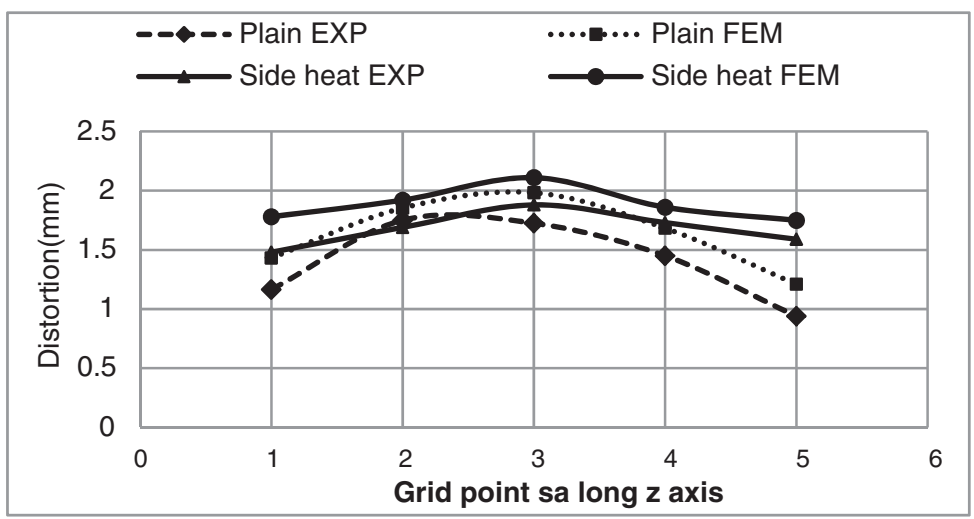

(c) Test Case 3 (Side heating at $70 \mathrm{~mm}$ )

Figure 10. a-e. Predicted and measured distortion for plain welding and welding with side heating. 


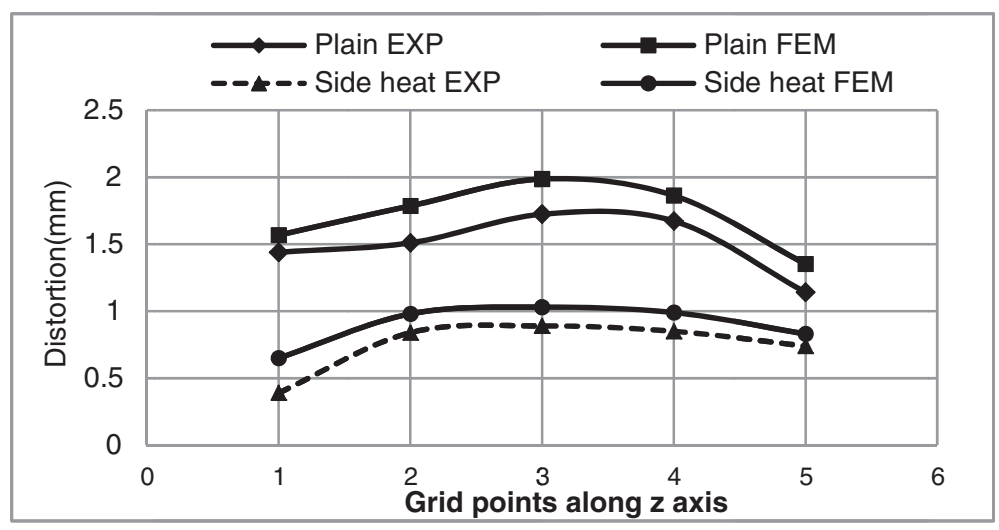

(d) Test Case 4 (Side heating at $80 \mathrm{~mm}$ )

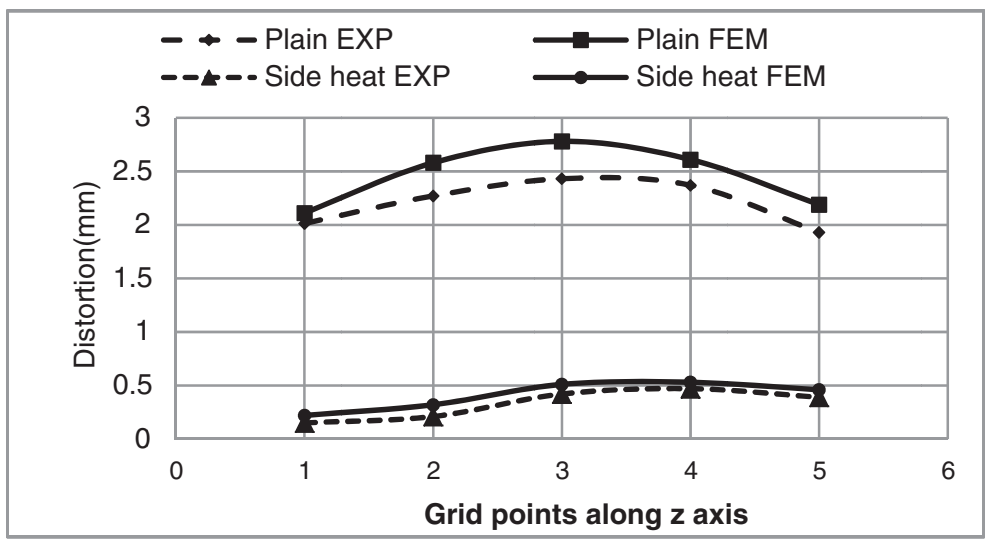

(e) Test Case 5 (Side heating at $90 \mathrm{~mm}$ )

Figure 10. (Continued.)

In figures 10a-e the measured and predicted angular distortions are plotted for five different test cases. Angular distortion is shown on $\mathrm{Y}$ axis whereas $\mathrm{X}$ axis shows grid points location along longitudinal direction. Both cases of 'plain welding' and 'side heating' welding are compared in these figures. Figures 10a-e indicate that, angular distortion has increased from maximum value (at middle grid point along length) of 1.231 to $2.431 \mathrm{~mm}$ when the weld current has increased from 150 to $185 \mathrm{amps}$. The increased heat input from test case one to five has resulted in raised angular distortion. For first test case (figure 10a) the side heating nozzles were placed at $50 \mathrm{~mm}$ form weld line in transverse direction. With short distance of $50 \mathrm{~mm}$ between sideheating flame and weld arc, more heat is added in close areas around weld. This added heat in short area has shown increased in the temperature gradient between the weld line and the area away from the weld line. Due to this, the specimens welded under plain welding condition have shown higher values of angular distortions in figure 10a.

This higher temperature gradient has caused the angular distortion to increase from 1.321 to $3.551 \mathrm{~mm}$ (figure 10a). Similarly, in test cases 2 to 4 the maximum distortion has found 2.98, 1.88, 0.89 and $0.42 \mathrm{~mm}$ for side heating distances of 60, 70, 80 and $90 \mathrm{~mm}$, respectively. From 


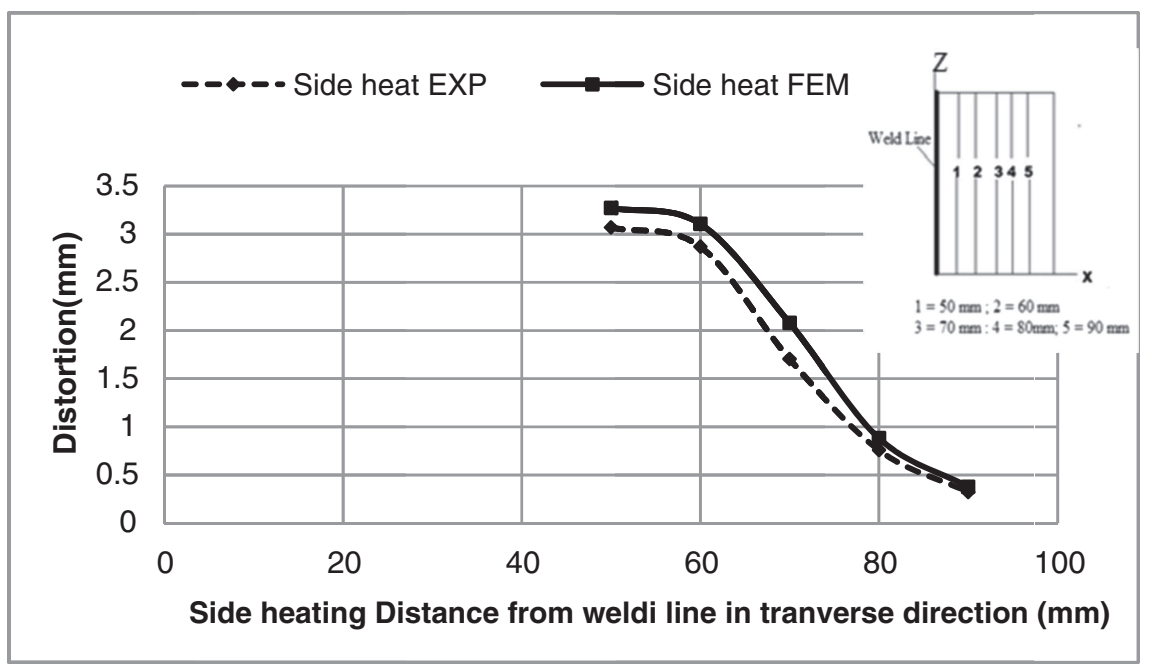

Figure 11. Effect of side heating nozzle distance on angular distortion.

figure 11 it can be observed that, as the side heating distance increases from 50 to $90 \mathrm{~mm}$ for test cases one to five, the average values of angular distortion has decreased from 3.07 to $0.324 \mathrm{~mm}$, respectively which is around $90 \%$. This may be due to the decreased temperature gradient between weld line and the unwelded edges of the workpieces. The considerable decrease in angular distortion will be helpful for producing the angular distortion free structures. Further extensive FEM trials can be performed using this FE model for optimising the side heating parameters to have minimum angular distortion. Also from figures 10a-e, it can be observed that, the FEM results are in close agreement with the experimental one in both side heating and plain welding conditions. Similarly, the predicted and measured values of average angular distortion (average of five grid points for one test case) in figure 11 are found in close agreement with each other.

\section{Conclusions}

The following conclusions are drawn from the present modelling and experimental investigations on multi pass manual metal arc welded butt joint.

(i) A 3-D finite element model for predicting the angular distortions of multipass manual metal arc welded ' $\mathrm{V}$ ' butt joints has been successfully developed which can be useful for control of welding distortion.

(ii) Layer-wise application of heat flux, incorporation of the joint geometry into the modelling and consideration of filler material deposition in the analysis led to temperature distribution profiles that closely matched the experimental values.

(iii) Average angular distortion has decreased to $90 \%$ with change in the side heating nozzle distance from 50 to $90 \mathrm{~mm}$ from weld line.

(iv) Close matching between modelled and measured angular distortions has been observed which confirms the validity of the model.

(v) Developed simulation of side heating phenomenon of welding can be used as a tool to control the angular distortion in butt welding. 


\section{References}

Adak M and Mandal N R 2009 Pseudolinear equivalent constant rigidity concept for analysing welding residual deformation. Appl. Mathematical Modelling 33: 2096-2108

Adak M and Mandal N R 2010 Numerical and experimental study of mitigation of welding distortion. Appl. Mathematical Modelling 34: 146-158

ANSYS 14 user's documentation 2013 SAS IP Inc, Canonburg, PA 15317, USA

ASM Metals Handbook Volume II-2005 Properties and Selection of Nonferrous Alloys and Special Purpose Materials. ASM International ISBN 0-87170-378-5

Camilleri D, Mollicone P and Gray T G F 2005 Computational prediction of out-of-plane welding distortion and experimental investigation. J. Strain Analysis 40(2): 161-176

Chakravarti A P, Malik L M and Goldak John A 1990 Distortion control in simulated one-pass panel bead welds. Marine Structures 3: 3-24

Costa J M, Pires J T B, Antunes F, Nobre J P and Borrego L P 2010 Residual stresses analysis of ND-YAG laser welded joints. Engineering Failure Analysis 17: 28-37

Damale A V and Nandurkar K N 2012 3-D Coupled FE analysis and experimental validation of restrained welding to control angular distortion. J. Institute of Engineers of India Series-C 93(4): 365-371

Dean Deng and Murukawa Hidekazu 2008a FEM prediction of buckling distortion induced by welding in thin plate panel structures. Computational Materials Sci 43: 591-607

Deng Dean and Hidekazu Murakawa 2008b Prediction of welding distortion and residual stress in a thin plate butt-welded joint. Computational Materials Science 43: 353-365

Goldak John, Aditya Chakravarti and Malcolm Bibby 1984 A new finite element model for heat sources. Metallurgical Transactions B 15B: 299-305

Jung G H and Tsai C L 2004 Fundamental studies on the effect of distortion control plans on angular distortion in fillet welded T-Joints. AWS Welding J. 213-223

Kim Seok-Hoon, Kim Jong-Bum and Lee Won-Jae 2009 Numerical prediction and neutron diffraction measurement of the residual stresses for a modified $9 \mathrm{Cr}-1 \mathrm{Mo}$ steel weld. J. Materials Processing Technology 209: 3905-3913

Long H, Gery D, Carlier A and Maropoulos P G 2009 Prediction of welding distortion in butt joint of thin plates. Materials and Design 30: 4126-4135

Mahapatra M M, Datta G L and Pradhan B 2006 Three-dimensional finite element analysis to predict the effects of shielded metal arc welding process parameters on temperature distributions and weldment zones in butt and one-sided fillet welds. Proc. IMechE Vol. 220 Part B: J. Engineering Manufacture, $837-845$

Mandal N R 2004 Welding and Distortion. Narosa Publishing House, New Delhi

Moraitis G A and Labeas G N 2009 Prediction of residual stresses and distortions due to laser beam welding of butt joints in pressure vessels. Int. J. Pressure Vessels and Piping 86: 133-142

Nishikawa H, Serizawa H and Murakawa H 2007 Actual application of FEM to analysis of large scale mechanical problems in welding. Science and Technology of Welding and Joining 12(2): 147-152

Radaj R 1992 Heat Effects of Welding, Springer-Verlag, UK

Tsai C L, Park S C and Cheng W T 1999 Welding distortion of a thin-plate panel structure. AWS Welding J. 156-165

Welding Handbook 2004 Welding Processes, American Welding Society, Volume 2-Part 1: ISBN: 0871717298

Zhang L, Michaleris P and Marugabandhu P 2007 Evaluation of applied plastic strain methods for welding distortion prediction. J. Manufact. Sci. Eng. 129: 1000-1010 